\title{
The Impact of using Bruner's Approach, Supported by Total Communication, on the Mathematics Achievement of Students with Hearing Disabilities in Amman Schools
}

\author{
Dr. Bahjat Altakhyneh \\ Department of Education \\ Arab Open University, Jordan
}

\begin{abstract}
This study aimed at investigating the impact using Bruner's approach, developed and supported with the total communication method, has on the achievement of hearing disabilities and hearingimpaired mathematics students, in Amman schools; and to investigate these students' attitudes towards this approach. The study sample consisted of 60 hearing disabilities students, randomly and equally assigned to two groups, an experimental and a control group. The experimental group is comprised of students that studied using Bruner's strategy supported by total communication. Conversely, the control group's students were taught with the traditional method, without integrating Bruner's approach. To answer the questions of the study, the researcher developed and used an achievement and attitudes scale specific to this study, for which validity and reliability were verified. The results show that there is a statistically significant difference $(a \leq$ 0.05 ) between the two arthematic means of hearing disabilities students on the achievement scale in favor of the experimental group, along with more positive attitudes of hearing disabilities students towards the approach used, with a trend ratio of $85.4 \%$. In light of the findings, the researcher recommends the use of modern educational strategies such as the Bruner approach, supported by total communication, in the rehabilitation and training of students with hearing disabilities.
\end{abstract}

Keywords: Mathematics; hearing disabilities; Attitudes; Bruner's Approach; Total communication.

\section{Introduction}

There are many challenges universally faced in the teaching of mathematics. These include raising the level of motivation for students, as well as developing new educational strategies to build a scientific understanding of concepts and the extrapolation of mathematical principles. The goal is to increase mastery of 
mathematical skills, and therefore the ability to solve mathematical problems, as well as to link mathematics learning to various other disciplines.

To better address this educational issue, it is necessary to take into account the individual differences among students in terms of achievement levels, mental abilities, intelligence, readiness to learn, and any physiological disabilities or challenges. There have been many appeals for the need to take into account the individual differences between students to conform to the principle of equity in education, and to preserve the right of each child to an appropriate education. Those calls have resulted in international standards such as the No Child Left behind Act of 2001 (NCLB), which requires the evaluation of students in mathematics, language skills, rehabilitation, and training (Etscheidt \& Curran, 2010). Therefore, attention must be paid to students with hearing disabilities, and to the design of special education programs that take into consideration their learning.

Among the most prominent problems facing students with learning disabilities, including those with hearing disabilities, is their isolation due to an inability to engage with their peers, in addition to the failure to inquire the mathematics skills raised by their math teacher, the results in a lack of motivation towards learning mathematics that gives rise to low achievement (Zeadah, 2005).

A study by Ariapooran (2017) points out that students with hearing disabilities have lower achievement scores than their normal-hearing peers, and have higher anxiety and fear while learning mathematics and lower motivation to learn mathematics than their peers. This accounts for the problems faced by these students, which calls a need for special treatment methods and strategies attuned to their culturally-specific learning needs. Such strategy would involve inviting experts and specialists in the field of teaching mathematics to collaborate with people with special needs to develop modern curricula that meet the needs and desires of this class of students globally and in the Arab region in particular.

Effective education depends on the provision of appropriate environments for active learner participation by communicating educational messages satisfactorily, means that educational content for learners is clearly conveyed, and is not confused due to an impairment of one of the senses, such as sight, or hearing.

In Jordan, students with hearing disabilities are saddled with a lack of curricula or specific strategies for teaching such students, as well as a lack of teacher experience in serving them. Those with hearing disabilities must have teachers trained on methods suitable for all their needs, which may combine linguistic and subject-specific strategies. A teacher trained in communicating with hearing disabilities students may still have a weakness in enacting proper teaching strategies used, especially in the field of mathematics. 
The National Council of Teachers of Mathematics (NCTM) emphasizes the need to take into account individual differences among learners, to provide learning opportunities for both ordinary and special needs students, as well as to individualize the educational programs offered and the strategies, content, and evaluation methods involved (NCTM, 2000).

Worldwide, about $2.5 \%$ of learners have some form of hearing problems, according to the World Health Organization, which are about 150 million people. This is an important group of individuals, for which there is a legitimate need to better integrate and train in various skills, such as writing, reading, and acquiring mathematical concepts and skills (Almasharawi \& Karaz, 2005).

Hearing is one of the most critical senses through which one learns language and speech, and it is used to understand the content of a message as presented by others in different situations of life; and this is especially true in education (Werner, 1988). Deaf is defined by partial or total absence, or loss, of hearing. This may be due to any number of causes, such as hereditary or genetic factors, are injury or disease at any stage of life including the pre-birth stage and fungal infections which may occur after birth, sometimes before learning to speak (Ezema , 2013).

An educationally-Deaf child is one born unconscious of hearing, or who lost hearing in childhood before acquiring speech, resulting in the inability to take advantage of spoken communication and to learn language in the traditional sense (Ezema , 2013). Hearing disabilities do not affect the physical development of hearing disabilities children, but have a direct impact on their verbal expression capabilities, and their cognition of special meaning or social cues as a result of not hearing sound, may result in a relative lack of social association, or a preference to work alone, or be separate from others (Riekeholf , 1993).

To better integrate the hearing disabilities with their community, it is necessary to develop communication skills through targeted communication methods and modern teaching strategies, includes the oral mode of communication with hearing disabilities that depends on the use of speech, lip-reading, and voice or audio training. The intention is to encourage the hearing disabilities to "read" speech by observing the movement of the lips, tongue, and palate, and to understand the communicated ideas by watching and reading the face, lips, and body positions. The speech levels in this method typically begin with comfortable and familiar words in new situations, which increase incrementally in informational and speech complexity (Alagany, 1999). It must be said that auditory training using the oral method most benefits those who have some partial hearing and may use a hearing aid, or those who lose their hearing after speech develops, because of the importance it places on sound to increase comprehension of language through reading of speech (Ugwuanyi, 2009).

Manual communication is another method used with hearing disabilities individuals; this depends on the use of sign language or physical gestures to communicate. This method may be used when hearing loss is total, or when 
hearing is moderately to severely impaired. Sign language is a system of symbols, or signs, to represent words, concepts, and ideas. These signs are formed from gestures, movements, and expressions of the body, hands, shoulders, and face. There are four types of signs:

1- Descriptive signs: describe an object or idea associated with sensory objects in the hearing disabilities mind.

2- Non-descriptive signs: particularly significant in hearing disabilities.

3- Meaningful signs: convey expressive movements of a noun or descriptors of a word.

4- Conventional signs: signs with functions in linguistic custom and not to visual cues, and which may be more difficult to comprehend by a hearing disabilities person. This can refer to the spelling of words by manipulating the fingers to represent the letters of the alphabet, used to express words, sentences, or phrases.

The two previous methods, the oral approach and the manual, may be merged to cover all communication (Mustafa, 2006). This strategy of "total communication" is supported by Bruner's approach, which is considered one of the most crucial learning approaches for students with hearing impairments because of its way of introducing mathematical concepts in sequence levels or modes of representation (Qutami, 2005). It involves the concrete, the pictorial, and the abstract, and this provides a high degree of communication through tangible object presentation, oral discussion, readable speech, and hand, eye, and eyebrow movements. For example, to introduce the concept of the number five (5), a teacher shows and describes five pens, then proceeds to reinforce this concept pictorially and abstractly. In that example, the students would be provided with total communication through the use of objects and sign language, be asked to draw the five pens, after which the teacher would use speech and language to tie in the abstract level and symbolize the concept of " 5 ". For a student with hearing disabilities to acquire the taught concepts fully, it is useful here to focus on providing immediate feedback to the learner, to mark the extent of progress towards achieving the desired goal.

\section{Using Bruner's approach to achieve total communication}

Bruner's theory is concerned with knowledge construction and learning through discovery. It involves organizing knowledge and its contents in a way that intuitively develops the learner's understanding of what is being taught. It shifts attention away from partial facts, and instead towards macro-facts and knowledge-building (Qutami, 2005).

Bruner identifies a set of necessary processes for effective learning, which lie in the acquisition of information by sequencing and continuing to present the concepts, transforming gained knowledge into useful knowledge by focusing on understanding and the exclusion of conservation, as well as evaluating progress and changes in knowledge in the domains of cognitive, emotional, and tangible skills (Alwan, 2008). This theory also focuses on thinking and inquiring skills, assuming the importance of facts in the development of thinking, so that the learner's cognitive understanding of the learning structure leads to progress in 
acquiring knowledge on his or her own. Bruner also considers that learning in school curricula involves a mental development that builds on the ability to deal with new life situations (Marai \& Alhailah, 1998).

To achieve proper mental development, one must avoid the direct influence of stimuli that are so severe that they lead to a negative impact on the thinking process. The focus must be on increasing a learner's ability to use words and symbols, developing the cognitive learner's structure by representing information and goals, and strengthening the relationship between learner and teacher because of its positive impact in the process of cognitive growth. Special attention must be paid to the level of language used in the learning process so as better aid the learner in understanding the concepts and the system of the educational environment. It is found that by increasing a learner's mental growth, he or she becomes more capable of performing multiple meaningful operations (Alqudah \& Altartori, 2007).

From the above we may conclude that Bruner's theory thoroughly addresses the conditions to be met in teaching concepts, problem solving, and curriculum development by creating a relationship between the previous and subsequent learned facts. It proposes the idea of building spiral-based curricula linking successive procedural steps or stages, starting from simple to detailed ideas, with the emphasis being on teaching experience.

Bruner's spiral design stresses the vertical relationship between concepts, or the continuity and sequence of the concepts presented, by repeating the concepts and their scope between rows. This differs from designs that convey a horizontal relationship between parts of knowledge, based on the repetition of partial ideas, topics, or concepts frequently, with increasing depth, as the curriculum progresses. The idea of the spiral approach, as based on Bruner's vision, is to refer to the main ideas when establishing what is new, so that knowledge starts from a small narrow point that grows deeper and wider as the curriculum progresses. This employment of a vertical approach increases and improves on the depth of knowledge and adopts the exploratory method as one of its applications (Qutami, 2005).

There are three essential steps in this model to ensure the transmission of knowledge to learners. The first step involves a tangibly teaching concepts and facts in way through observation and interaction with physical objects, when possible. This step encourages hearing disabilities students to learn using their available senses, by direct communication, and this increases the motivation to learn and for the discovery of facts. The second step is semi-sensory, where the focus is on images, graphics, shapes, and the use of technology such as computers in the transfer of concepts and acquisition of skills to students. This may involve having the student draw understand, for example, the concept of numbers, calculations, fractions, and so on. Finally, the third or abstract step is where the student utilizes the learned knowledge of the previous two phases to communicate with abstract concepts, such as mathematical symbols, using various communication methods. 
A study by Mulwa (2015) reviewed the literature related to educational difficulties faced by students as a way to address students' academic vulnerability in Kenyan schools. The results of the study showed that there were problems in the use of mathematical terms and concepts, and proposed modern methods such as the use of constructional theory in teaching, to help teachers and curriculum planners in mathematics.

There are many strategies and methods that are used to teach hearing disabilities students. Shelton and Mary (2016) conducted a study on the possibility of benefiting from mobile phone applications in the teaching of hearing disabilities, as well as to explore the views of the teachers and hearing disabilities students themselves about the importance of mobile apps use. The results showed that mobile apps provided a suitable environment for learning and were useful in acquiring self-learning skills and taking into account individual differences. Thus, the study recommended employing of such programs for hearing disabilities students.

Thai et al. (2016) conducted a study to identify the effectiveness of teaching using "magic finger" signals, a approach incorporating the total communication method, and to note students' perceptions about this method as used to help hearing disabilities students master multiplication skills. This method was applied to 70 students from schools in Malaysia, and the results confirmed the effectiveness of incorporating a "total communication" method. The study also recommended that parents, teachers, students, and individual education institutions should be aware of the importance of participating in the planning and design of educational programs for hearing disabilities students.

Giraldo and Bermudaz (2014) conducted a study with the intention to explore the learning curve by utilizing the concept of "function" as a mathematical position. They aimed to shed light on how problems arising from mathematics education, both social and cultural, can be reduced for hearing disabilities students through teacher intervention using specific order of sequences to transfer learning experiences, along with the use of a computer learning environment. The researchers recommend using the theoretical framework provided by Brousseau's Theoretical Framework in educational situations for the hearing disabilities, and Duval's records of semiotic representation in teaching geometry in particular.

Marschark et al. (2015) attest that the achievement of hearing disabilities students is the result of a complex interaction of a range of factors. These factors include hearing thresholds, level of language fluency, nature of their communication with others, and the characteristics of their family environments such as the level of parents' "hearing disabilities education" economic level, and experiences within and outside the school. This study examines the relative importance of these factors in the teaching of hearing disabilities students the subjects of mathematics, science, and social studies within the schools of the United States of America. 
A study carried out by Pagliaro \& Kreitzer (2013) found that students with hearing impairments, at various grade levels, had weak achievement and poor performance in mathematics skills. The study indicates that weakness in progress starts before commencing school education. The results showed that such students have more significant gap in the areas of problem solving, measurement, and preparation compared to their peers in the subject of geometry.

Batekh (2001) conducted a study to explore the reality of teaching mathematics and language to hearing disabilities students at elementary schools and to identify the linguistic problems associated with learning mathematics. The results showed the need to plan mathematics classes and provide training courses for teachers in light of the benefits of advanced international programs in communication with the hearing disabilities; and the teaching and development of remedial models for students' errors in reading and writing mathematics.

Shehata (1998) proposed a program for teaching geometry to special needs students, adopting nontraditional curricular and teaching programs in mathematics. That researcher asserts that the current reality does not take into consideration the interests of hearing disabilities students, which leads hearing disabilities students to lose interest in education and exhibit a severe deficiency in mastering necessary skills. The results of the study show the need to build courses and methods attuned to the tendencies and needs of hearing disabilities students, so they may better accept and acquire the basic mathematics skills and knowledge presented. The study called for the need to train teachers who teach mathematics to the hearing disabilities, and to nurture the specific environment surrounding these students to encourage their learning.

Dababneh \& Alhassan (2009) conducted a study aimed at identifying teachers' perspectives about the integration of students with hearing disabilities in regular schools in Jordan. It showed that while they viewed this merging positively, they also cautioned that appropriate steps must be taken in consideration for the individual needs of these students, in order to ensure curriculum retention.

\section{Study Description}

The mathematical problems and difficulties facing students, in general can be addressed by using Bruner's approach for education and the construction of mathematical knowledge. This study deals with the issues hearing disabilities students face in learning mathematics by proposing programs and curricula that take into account their educational problems, and by providing learning alternatives through the use of other senses. It is this researcher's hope that the approach of integrating Bruner's approach and total communication does increase the achievement of hearing disabilities students in Jordan.

\section{Study Problem:}

The problem of the study is the weakness of the programs and teaching strategies provided to hearing disabilities students in Jordanian schools. Hearing disabilities students and those with hearing impairments suffer from a 
decreased mathematical achievement level, as evidenced in their relative inability to understand mathematical concepts and to master mathematical skills. Also, students with hearing disabilities, as with students with learning difficulties in general, suffer from a lack of useful programs and strategies for the development of students' concepts and skills. Teachers are well-trained in communication skills but have a weakness in the appropriate teaching strategies for teaching special needs populations- particularly in mathematics.

Some of the global problems observed in teaching hearing disabilities students are the lack of trained teachers to teach mathematics and the lack of specific programs for them in the field of mathematics teaching. This study is designed to examine how the Bruner approach and the total communication method may serve in developing such a program in Amman schools.

\section{Objectives of the study:}

This study aims to develop programs and teaching strategies in the field of mathematics to suit students with hearing disabilities in Jordan. The philosophy of education in Jordan emphasizes the need to consider students with special needs, including hearing disabilities students or those who have lost part of their hearing. During the speech, concepts and activities must be clarified through other modalities, such as the sense of sight.

The study aims, particularly, to investigate the effect of using the Bruner approach, as supported by the total communication method, on the mathematical achievements of students with hearing disabilities in the Amman schools.

\section{Study Questions:}

1) What is the impact of using Bruner's approach of support by total communication, in the development of mathematical achievement among students with hearing impairments in Amman schools?

2) What are the attitudes of students with hearing disabilities towards Bruner's approach, supported by total communication, in Amman schools?

\section{Terminology of study:}

Bruner's approach supported by total communication: Entails procedures and steps carried out by the mathematics teacher inside the classroom, as well as the covered activities, examples, and exercises, wherein the teacher thoroughly serves the learning needs of hearing disabilities students through total communication. This approach is based on the following steps:

1. Providing the necessary prerequisites for new learning.

2. Presenting the concepts serially, in the order of the concrete, then the pictorial, and then the abstract.

3. Speaking with hearing disabilities students through oral language, manual language, drawing, and writing (Total Communication).

4. Graduating the presentation of activities from simple to complex.

5. Providing immediate feedback.

6. Using the methods of formative and summative evaluation.

Students with hearing disabilities (hearing disabilities): The category of students who have lost the sense of hearing, in whole or in part, from birth, or those who 
have lost the sense of hearing after birth. In the current study, the hearing disabilities student is one who has been diagnosed by specialists as having a total or partial loss of hearing (Ademokoya \& Shittu, 2008).

Achievement: The set of all concepts, skills, principles, and experiences acquired by the learner after passing through educational tasks. In the present study, it is recognized as the degree to which the learner obtains a degree in the achievement test, which prepared for this purpose by the researcher.

Attitudes of students: The hearing disabilities students' feelings towards, and willingness to accept or reject, the approach used. The attitudes are measured via questionnaire, on which the teachers answer based on their impressions about the success of approach and how well it is embraced by their students, on a scale prepared for this purpose by the researcher.

\section{Study determinants:}

The results of the study are determined by the following:

- $\quad$ The validity and reliability of the used tools

- $\quad$ The study sample of students with hearing disabilities for the 2018/2019 academic year in Amman educational schools

- Academic achievement scores that cover concepts, skills, and mathematical generalizations in the unit numbers and operations.

\section{Methodology:}

\section{Subjects:}

The study sample consists of 60 students enrolled in the resource rooms of individual education schools in Amman, who are identified as hearing disabilities or with hearing disabilities. They were classified by the teachers of the resource rooms as having hearing problems. They were divided into two equal groups of 30 , an experimental and a control group.

\section{Study Tools:}

The following tools were used in the present study:

Processing tool: A teacher's manual that was prepared on the subject of numbers and transactions according to the following steps:

- Define the behavioral objectives of the issue of numbers and operations.

Example: $\quad$ The learner should write numbers 1 through 5.

The learner should add two numbers up to 9.

The learner should add two numbers up to 99.

And so on....

- Determine the tools used in teaching the subject of the lesson

Example: Processing materials such as colored balls, juice cans, pencils,...

- Identify the necessary prerequisites. 
- Determine the required activities and procedures for the subject of the lesson (Identification of approach used: Bruner's approach supported by total communication)

Example: To teach the addition of two numbers between 1 and 9 .

Step 1: Using combinations. For example, the teacher presents three red balls and four blue balls, and mixes them in front of the students. Students would notice that the process involves combining elements and asking the students to describe what they see, using the sign language to communicate with the students.

Step 2: Using the pictorial or drawings. The teacher presents an image or picture of three red balls, as well as for four blue balls, then merges them together through the pictures, and asks one of the students to draw them all together again by lip communication and sign language. Then an image of a tree is presented with three birds on it, and another tree with four birds, which are all then shown to fly to another tree. The students are then asked to count all the birds by using sign language. The use of a computer is possible in this step.

Step 3: Using mathematical symbols. The teacher writes $3+4=7$, and clarifies with sign language the symbols used, such as the concept of the process " + " as combining two sets of elements. The teacher then asks the students to perform some calculations as a form of formative evaluation:

Display the process " $1+2=3$ " by using pencils or balls

Draw the process " $1+2=3$ " on the notebook, using drawings of whichever objects are preferred by the learner

Write the result of $2+2=\ldots, 3+5=\ldots, 7+2=\ldots$ and so on.

- Evaluation of students' learning through formative evaluation, summative evaluation, and the worksheets implemented according to the three levels of the Bruner approach supported by total communication.

- Giving homework to the students. It is possible to use computers and the Internet to send students' homework, have them complete it, and to follow up on students' results through learning management sites.

\section{Measurement tools:}

Achievement: A test was conducted to determine academic performance in the subject of numbers and operations. This test covered concepts, skills, and the use of generalizations in the unit. This test consists of 20 paragraphs- eight paragraphs concerning mathematical concepts, eight items measuring mathematics skills, and four items measuring the use of accurate generalizations in life situations. Validity and reliability of the scale was verified.

Attitudes of students towards the approach used: A questionnaire was developed for the teachers to determine students' attitudes towards the approach used. The standard included 17 paragraphs with a triple scale. The instrument was validated using the sincerity of the researcher and the reliability coefficient (0.83).

\section{Study variables:}

The independent variable is a teaching approach, and has two levels: 
- An adapted Bruner's approach of total communication.

- The usual teaching method.

The dependent variables in this study are:

- Achievement.

- Teachers' impressions of student attitudes towards the approach used.

\section{Study Procedures:}

- The preparation of educational content on the subject of numbers and processes, including the concepts and skills involved. Subsequently, the presentation of content to arbitrators who are specialized in the curricula and methods of teaching mathematics and the difficulties inherent to learning mathematics.

- The preparation of a mathematical achievement scale, edited and revised according to arbitrators, and its application to a prospective sample to determine the time of its application and the coefficient of reliability, so as to apply a priori to study individuals.

- The preparation of a measure of the attitudes towards the approach used. which is done by examining the mathematics subjects in the preparation and operations unit in addition to the previous tests in this field, then applying it to the sample of the previous survey, and presenting it to the arbitrators and calculating its stability and credibility.

- The selection of study subjects in a deliberate manner, equally dividing them randomly into two groups, an experimental and a control, all while ensuring parity between them in terms of some variables such as previous achievement in mathematics in the last school year.

- The preparation of the teacher's guide according to Bruner's approach, with total communication, which is presented to judgment in the field of teaching mathematics. Note that the teacher would be tasked with supplying all necessary steps in the course of teaching mathematics, such as providing the sense-stimuli objects and the illustrations to support the sign language.

- Teacher training for the Learning Disabilities Teachers, covering the teaching process of students of the experimental group on how to use the Bruner approach, adapted for the means of comprehensive communication.

- Teaching the topic of numbers and processes to the experimental group using the Bruner total communication strategy, as detailed by the teacher's guide, while teaching the students of the control group by way of the usual method of teaching.

- Administration of the scale of achievement test in mathematics for all students at the end of the teaching term, as well as measuring attitudes towards the approach used.

- Analysis of study results.

- Submission of proposals and recommendations.

\section{Conclusion and discussion}

This study aims to answer two critical questions about the use of Bruner's approach of total communication. The first involves exploring its effects on the mathematical achievement levels of Amman students with hearing disabilities, 
while the second delves into the attitudes of the teachers and students about that approach in use.

\section{First question results:}

What is the impact of using Bruner's approach support by total communication, in the development of mathematical achievement among students with hearing disabilities in Amman schools?

The arithmetic means and standard deviations of student scores were found for the achievement tests of each of the experimental and control groups. Table 1 shows this.

Table 1: Descriptive Statistics of Experimental and Control groups for Pre- and PostAchievement.

\begin{tabular}{|l|l|l|l|l|}
\hline Group & $\mathrm{N}$ & Mean & Std. Deviation \\
\hline \multirow{3}{*}{ Experimental } & Pre-achievement & 30 & 58.23 & 11.55 \\
\cline { 2 - 5 } & Post-achievement & 30 & 69.80 & 9.71 \\
\hline \multirow{3}{*}{ Tontrol } & Pre-achievement & 30 & 57.43 & 11.06 \\
\cline { 2 - 5 } & Post-achievement & 30 & 58.20 & 10.27 \\
\hline & Pre-achievement & 30 & 57.83 & 11.22 \\
\cline { 2 - 5 } & Post-achievement & 30 & 64.00 & 11.50 \\
\hline
\end{tabular}

It can be seen in the above table that the mean of the experimental group increased by (11.57) between pre-achievement (58.23) and post-achievement (69.8). The arthematic mean of the control group, on the other hand, increased by (0.77) between pre-achievement (57.43) and post-achievement (58.20). This shows a much greater increase by the experimental group over the control group, with a deference of (10.8).

To explore the significance of the differences between the arithmetic means of the experimental and control groups, (ANCOVA) was used, as shown in the following table:

Table 2: Analysis of Covariance between Means of Experimental and Control Groups for Post-Achievement

\begin{tabular}{|l|l|l|l|l|l|}
\hline Source & Sum of Squares & df & $\begin{array}{l}\text { Mean } \\
\text { Square }\end{array}$ & F & Sig. \\
\hline Corrected Model & 5352.56 & 2 & 2676.28 & 62.02 & $.000^{*}$ \\
\hline Intercept & 1363.30 & 1 & 1363.30 & 31.59 & $.000^{*}$ \\
\hline Pre-achievement & 3334.16 & 1 & 3334.16 & 77.27 & $.000^{*}$ \\
\hline Variable Group & 1833.75 & 1 & 1833.75 & 42.49 & $.000^{*}$ \\
\hline Error & 2459.43 & 57 & 43.14 & & \\
\hline Total & 253572.00 & 60 & & & \\
\hline Corrected Total & 7812.00 & 59 & & & \\
\hline
\end{tabular}

* Significance at the level of $(a \leq 0.01)$.

The results in Table 2 indicate the existence of a statistically significant effect in the variable group ( $\mathrm{f}=42.49, \mathrm{a}=0.000$ ), in favor of the experimental group that used Bruner's approach with the support of total communication.

Modern approach of Bruner's to support hearing disabilities students by using alternative tools to more successfully impart mathematical concepts and skills. 
The approach of developing and adapting Bruners' approach with total communication as a teaching method helps provide deep student understanding, by relating previous knowledge with later knowledge.

The approach also encourages students to collaborate and engage with tasks positively. A study by Marschark et al. (2015) indicates that hearing disabilities students can understand and apply mathematics by increasing their language skills and communication with peers, just as the approach used in this study also emphasizes the importance of communication skills when introducing mathematical content.

The importance of using modern strategies with hearing disabilities students is consistent with findings in previous studies. These studies include one by Shelton and Mary (2016), which used a mobile application for teaching hearing disabilities students, and the research of Thai at el. (2016), which points out the importance of using TC (total communication) in increasing the achievement of hearing disabilities students in mathematics.

This result can be attributed to the effective use of Bruner's approach as supported by total communication modalities, as the approach provides progressive learning steps from the concrete, to the pictorial, then the abstract; and the sequential nature of this approach helps hearing disabilities students acquire, retain, and develop their mathematics skills.

In fact, as findings by Ugwuanyi (1999) revealed, total communication may be more favored by teachers than oral and manual strategies because it is assumed that with the use of total communication, there is more likely to be an improvement in the academic achievement of children with hearing impairment; because of the holistic approach of this method if students don't understand through sign language, they may realize either through speech, gestures, or any other means that are available to them. Naturally, enhancement of academic achievement is the key issue in every teaching method.

\section{Second question results:}

What are the attitudes of students with hearing disabilities towards Bruner's approach, supported by total communication, in Amman schools?

The following table shows the average means and standard deviations of the attitudes toward this approach of teaching:

Table 3: Arithmetic Means and Standard Deviations of Attitudes toward the Approach, in Descending Order.

\begin{tabular}{|l|l|l|l|}
\hline $\begin{array}{l}\text { Paragraph } \\
\text { no. }\end{array}$ & Paragraph & Mean & $\begin{array}{l}\text { Std. } \\
\text { Deviation }\end{array}$ \\
\hline q13 & $\begin{array}{l}\text { I noted that Hearing disabilities students have } \\
\text { acquired skills easily when I use Bruner's approach, } \\
\text { with total communication. }\end{array}$ & 4.90 & .30 \\
\hline q14 & $\begin{array}{l}\text { Bruner's approach of comprehensive contact } \\
\text { provides an educational opportunity for Hearing } \\
\text { disabilities students. }\end{array}$ & 4.83 & .46 \\
\hline
\end{tabular}




\begin{tabular}{|c|c|c|c|}
\hline q10 & $\begin{array}{l}\text { The approach used has given me more time to } \\
\text { connect with students and increase their thinking } \\
\text { ability }\end{array}$ & 4.70 & .65 \\
\hline q16 & $\begin{array}{l}\text { I believe that Bruner's approach, supported by total } \\
\text { communication, helps Hearing disabilities students } \\
\text { acquire mathematical skills. }\end{array}$ & 4.56 & .56 \\
\hline q12 & $\begin{array}{l}\text { Bruner's approach, supported by full } \\
\text { communication, helped me easily communicate } \\
\text { mathematical ideas. }\end{array}$ & 4.56 & .81 \\
\hline q9 & $\begin{array}{l}\text { The teaching approach employed has provided } \\
\text { more excellent interaction with students with } \\
\text { hearing disabilities. }\end{array}$ & 4.46 & .97 \\
\hline q5 & $\begin{array}{l}\text { This approach presented Mathematical concepts in } \\
\text { a way that suits the needs of students with hearing } \\
\text { disabilities }\end{array}$ & 4.43 & .62 \\
\hline q15 & $\begin{array}{l}\text { Bruner's approach, supported by total } \\
\text { communication, provides learning tools that take } \\
\text { into account Hearing disabilities students and their } \\
\text { special circumstances. }\end{array}$ & 4.40 & .77 \\
\hline q11 & $\begin{array}{l}\text { Bruner's approach, supported by mass media, } \\
\text { helped me clarify mathematical concepts. }\end{array}$ & 4.40 & .62 \\
\hline q17 & $\begin{array}{l}\text { I noticed an increased level of motivation for } \\
\text { hearing disabilities students when I used Bruner's } \\
\text { approach, supported by full communication. }\end{array}$ & 4.26 & .44 \\
\hline $\mathrm{q} 4$ & $\begin{array}{l}\text { I note that students have been able to understand } \\
\text { mathematical concepts clearly. }\end{array}$ & 4.23 & .62 \\
\hline q7 & $\begin{array}{l}\text { The approach used provided an opportunity for } \\
\text { comprehensive evaluation: initial - formative - final. }\end{array}$ & 4.06 & .63 \\
\hline q1 & $\begin{array}{l}\text { The teaching approach provides the right time to } \\
\text { teach students with a notable hearing disability. }\end{array}$ & 3.93 & 1.112 \\
\hline q3 & $\begin{array}{l}\text { I expect students to gain more by using the } \\
\text { approach used. }\end{array}$ & 3.86 & 1.45 \\
\hline q6 & $\begin{array}{l}\text { I note that the procedure used increased the } \\
\text { motivation of students to learn and to do activities. }\end{array}$ & 3.80 & .88 \\
\hline q8 & $\begin{array}{l}\text { I have a desire to use this approach in the future for } \\
\text { the purpose of TdL (Teaching Hearing disabilities } \\
\text { Learners). }\end{array}$ & 3.63 & .96 \\
\hline $\mathrm{q} 2$ & $\begin{array}{l}\text { The approach used provides adequate feedback to } \\
\text { students with hearing disabilities. }\end{array}$ & 3.53 & 1.96 \\
\hline Total & & 4.27 & .30 \\
\hline
\end{tabular}

We notice that from the above table that the total arithmetic mean was (4.27), and the standard deviation (0.3), and with a percentage of $85.4 \%$. This indicates relatively positive attitudes towards the approach of using Bruner's approach supported by total communication.

It was perceived that this approach increases the motivation of hearing disabilities students learn mathematics, by developing adequate accommodation to their impairment while solving their problems in mathematics. 


\section{Recommendation}

The researcher recommends using Bruner's approach and the total communication method to teach hearing disabilities or hearing-impaired students' mathematics subjects, to provide them with an appropriate classroom environment, while taking into account their individual circumstances and differences. The approach offers an alternative means of learning through a mixing of sensations, illustrations, and communication, and has been shown to increase a student's motivation to learn.

\section{References}

Ademokoya, J., \& Shittu, B. (2007). Onset of hearing loss, gender, and self-concept as determinants of academic achievement the English Language of students with hearing disability in Oyo State, Nigeria.

Alagany, A. (1999). Deaf curricula: planning, building, and implementation. Amman: World of Books.

Almasharawi, E., \& Karaz, B. (2005) A proposed program in mathematics for the first grade in Deaf schools in the Gaza governorates. Arab Special Education Conference: "Reality and Hope" 26-27/4/2005, University of Jordan.

Alqudah, H., \& Altartori, M. (2007). Fundamentals of educational psychology: theory and practice. Amman: Dar Alhamid.

Alwan, A. (2008). Educational Psychology. Amman: Dar Alhamid.

Ariapooran, S.(2017).Mathematics motivation, anxiety, and performance in female Deaf/hard-of-hearing and hearing Students, Communication disorders quarterly, 38(2), 172-178.

Batekh, F. (2001). Field study of some linguistic problems in the teaching of mathematics for Deaf students in the primary stage and proposed methods of treatment based on some programs, advanced communication with them, Journal of psychological and educational research, 16(1), 38-94.

Dababneh, Kh., \& Alhassan, S. (2009). Integrating students with hearing disabilities into regular schools from the point of teachers view, Journal of Educational Sciences, $5(1), 1-14$.

Etscheidt, S., \& Curran, C. M. (2010). Peer-reviewed research and individualized education programs (IEPS): An examination of intent and impact, Exceptionality (A Special Education Journal), 18(3), 138-150.

Ezema, O. (2013). "Effect of total communication and achievement of pupils with learning impairment in Enugu State", Master dissertation, University of Nigeria.

Giraldo, R., \& Bermudez, E. (2014). The social and cultural problems of the Deaf population in the learning of mathematics are minimized with teacher intervention, Revisit Latino Americana de Etnomatemática, 7(2), 29-43.

Marai, T., \& Alhailah, M. (1998). Individualized Education. Amman: Dar Al Fikr.

Marschark, M., Shaver, D., Nagle, \& K., Newman, L. (2015).Predicting the Academic Achievement of Deaf and Hard-of-Hearing Students from Individual, Household, Communication, and Educational Factors, Exceptional Children, 81(3),350-369.

Mulwa, E. (2015).Difficulties encountered by students in the usage of mathematical terminology: A Critical literature review, journal of education and practice, 6(13), 60-75.

Mustafa, A. (2006). Strategies of Deaf teaching, series of teaching strategies for people with special napproacheeds. Assiut University. 
Pagliaro, M., \& Kritzer, L.(2013).The Math gap: A description of the mathematics performance of preschool-aged Deaf/hard-of-hearing children, Journal of Deaf studies and education, 18(2), 139-160.

Qutami, Y. (2005). Learning and education theories. Amman: Dar Al-Fikr.

Riekeholf, L. (1993). The illustrated guide the mastery of sign language and manual alphabets. Springfield: Gospel Publishing House.

Shehata, K. (1998). Proposed geometry program for students with special needs, Journal of the faculty of education in Assiut, 14(2), 286-310.

Shelton, B., \& Mary, A. (2016) Teaching math to Deaf/hard-of-hearing (DHH) children using mobile games: Outcomes with student and teacher perspectives, International journal of mobile and blended learning, 8(1), 1-17.

Thai, L., Yasin, M., \& Hanafi, M.(2016). Magic finger teaching method in learning multiplication facts among Deaf students, Journal of Education and Learning, 5(3), 40-50.

Ugwuanyi, L. (2009). "Effect of the three sign language modes on the reading comprehension of pupils with hearing impairment in Enugu state primary school for the Deaf." Unpublished PhD Thesis, University of Nigeria, Nsukka.

Werner, D. (1988). Disabled village children. Palo, Fall: Hespenan Chapman.

Zeadah, Kh. (2005). Learning difficulties in mathematics. Cairo: Dar Aitrak Publishing, Distribution, and Printing. 